\title{
Early hematoma expansion in primary intracerebral hemorrhage: incidence and predictors
}

\author{
Hany Hamed Abd Elhady Helal ${ }^{1}$, Wafik Said Bahnasy ${ }^{2,3^{*}}$ (D), Azza Abbas Ghali ${ }^{2}$ and Mohammed Osman Rabie ${ }^{2}$
}

\begin{abstract}
Background: Hematoma expansion (HE) is the leading cause of early neurological deterioration, poor functional outcome, and increased mortality in patients with spontaneous intracerebral hemorrhage (S-ICH). The study aimed to estimate the risks and predictors of early $\mathrm{HE}$ in patients with $\mathrm{S}-\mathrm{ICH}$ and the effect of this HE on patient's survival and functional outcome.
\end{abstract}

Methods: This study was carried out on 72 patients with S-ICH submitted to baseline non-contrast brain CT (NCCT) and CT angiography for determination of hematoma site, size, border irregularity, blend sign, and spot sign score (SSS). Rescan was done $48 \mathrm{~h}$ after stroke onset or on clinical deterioration to resize the HV and diagnose HE. Modified Rankin Scale (MRS) was done 3 months after stroke onset to assess the effect of HE on patients' physical dependence.

Results: HE occurred in 28/72 (38.9\%) of included patients. Risks of HE included old age, smoking, elevated baseline mean arterial blood pressure, and high admission modified National Institute of Health stroke scale. NCCT predictors of $\mathrm{HE}$ included large volume, irregular border, and presence of blend sign. The presence of spot sign in early CTA is more accurate than NCCT predictors with 54\%, 91\%, 79\%, and 75\% for sensitivity, specificity, positive predictive value, and negative predictive value, respectively.

Conclusions: HE is a major cause of early clinical deterioration, increased mortality, and poor functional outcome. Early CTA for detection of spot sign is indicated in patients with large volume, irregular border, and/or blend sign in NCCT.

Keywords: Hematoma expansion, Spontaneous intracerebral hemorrhage, Blend sign, CT angiography, Spot sign

\section{Introduction}

Spontaneous intracerebral hemorrhage (S-ICH) is defined as rapidly developing neurological signs attributable to a focal collection of blood within the brain parenchyma and/or the ventricular system that is not caused by trauma [1]. It is the second most common type of stroke accounting for $10-15 \%$ of cases and usually carries high risks of severe functional disability and mortality [2].

Hematoma expansion (HE) due to re-bleeding occurs in up to $30 \%$ of cases of S-ICH during the early hospitalization period. There is a controversy about the amount of HE needed to produce poor outcome but that between 13 and $32 \%$ range is the most commonly used

\footnotetext{
* Correspondence: wafiq.elbahnasi@med.tanta.edu.eg

${ }^{2}$ Faculty of Medicine, Tanta University, Tanta, Egypt

${ }^{3}$ Department of Neurology, Faculty of Medicine, Tanta University, Tanta

31527, Egypt

Full list of author information is available at the end of the article
}

[3]. HE is one of the major determinants of early neurological deterioration, poor functional outcome, and increased mortality after S-ICH [4]. To date, no consensus about the best interventional therapy that improve $\mathrm{S}-\mathrm{ICH}$ outcomes, but early prediction of HE seems to be the logical first step. HE is more common among S-ICH patients with history of warfarin use, high admission systolic blood pressure, and low admission Glasgow Coma Scale. The non-contrast CT (NCCT) HE predictors are not clearly defined with controversial results about their sensitivity, specificity, and accuracy. These NCCT possible predictors included large hematoma volume (HV), heterogenous density, shape irregularity, intraventricular extension, niveau formation, and each of satellite, island, blend, swirl, or black hole signs [5]. In recent years, contrast leakage during CT angiography (CTA) inside the hematoma resulted in spot sign that had been 
extensively researched and seems to be a promising early predictor of $\mathrm{HE}$ which could be relied on updating $\mathrm{ICH}$ early intervention before irreversible cerebral damage takes place [6].

The aim of the work was to study the incidence of hematoma expansion after primary intracerebral hemorrhage, the predisposing factors to its occurrence, and its effect on patient's survival and degree of disability.

\section{Methods}

This paper is adapted from the thesis with the same title submitted by the first author to the Faculty of Medicine, Tanta University, in partial fulfillment of the Master's degree in Neuropsychiatry. The work was a prospective cohort study conducted on 72 patients with S-ICH admitted to the neurovascular units and/or the ICUs of the Neurology Unit, Neuropsychiatry Department, Tanta University Hospitals in the period from December 2016 to September 2018.

Exclusion criteria encompassed patients with traumatic intracranial hemorrhages, subarachnoid hemorrhages, hemorrhagic transformation of a recent ischemic stroke, or hemorrhage inside a space occupying lesion. Patients who were vitally unstable or died before the follow-up CT as well as those who had contraindications to iodinated IV contrasts were also excluded.

The study's protocol was approved by The Research Ethics Committee and Quality Assurance Unit, Faculty of Medicine, Tanta University. Informed consents were obtained from all patients' legal relatives, participations were voluntary, and possible risks were clarified.

Clinical assessments of the patients were done on admission through history taking and initial as well as 48-h post-stroke severity assessment using the modified National Institute of Health stroke scale (m-NIHSS) [7]. After admission, patients received treatment based on the American Heart Association/American Stroke Association guidelines for early S-ICH, 2015 [8]. Survived patients underwent follow-up visits for 3-months post-stroke, at the end of which the degree of physical disability was assessed using the Modified Rankin Scale (MRS) [9].

Radiological evaluations were accomplished through doing initial NCCT to establish the diagnosis and to determine the hematomas sites, volumes, and heterogenicity by estimation for the presence of blend sign. The HV was calculated according to the equation; $A B C / 2$ where $A$ was the largest diameter, $B$ was the maximal diameter perpendicular to $A$, and $C$ was the vertical depth (which was calculated by the number of $5-\mathrm{mm}$ interval slices). The sites were classified to lobar, deep (thalamo-ganglionic), and infratentorial (cerebellar and brainstem). Concerning the blend sign, it was defined as hematomas with blending regions of different hyper-densities separated by a well-defined margin that is easily recognized by the naked eye.
The difference between the two areas is more than 18 but less than 28 Hounsfield Unit [10]. Early CTA were done to included patients within $6 \mathrm{~h}$ of admission for detection of spot sign and estimation of the spot sign score (SSS) (Additional file 1) [11]. NCCT rescan were done $48 \mathrm{~h}$ after stroke onset or if clinical deterioration took place whichever occur first. HVs were remeasured, and accordingly, included patients were divided in the following groups: $28 / 72$ (38.9\%) cases developed HE (HE-group) and 44/72 (61.1\%) cases did not develop HE (non-HE-group). HE was defined as increased baseline HV by $\geq 6 \mathrm{ml}$ or $33 \%$ in follow-up images associated with worsening of the patient's neurological state [12]. Each group were further subdivided regarding the most possible hematoma etiology and relied on the SMASH-U classification to hypertensive (HTN), structural vascular lesions, systemic diseases, and medication-induced ICH [13]. The NCCT and CTA were performed using GE Medical System (Waukesha, WI, USA).

Statistical analysis was conducted using SPSS Prism, version 20, 2013 created by IBM, Chicago, IL, USA. Statistical differences between the studied groups were tested using chi-square for categorical variables and unpaired Student $t$ test for numerical variables. Sensitivity and specificity were measured using MedCalc's Diagnostic test, and correlation analysis was performed using Pearson's correlation test. $P$ values $<0.05$ were considered statistically significant.

\section{Results}

Demographic data of the included patients showed that their age was $56.96 \pm 9.36$ years, $39 / 72(54.2 \%)$ were females, $33 / 72(45.8 \%)$ were males, $23 / 72$ (31.9\%) were diabetics, and 19/72 (26.4\%) were smokers with mean smoking index $36.3 \pm 14.8$ (for smokers). The onset/hospital arrival time was $4.3 \pm 2.6 \mathrm{~h}$, the admission mNIHSS was $17.2 \pm 2.5$ points, and baseline mean arterial blood pressure $(\mathrm{ABP})$ was $118.5 \pm 24.8 \mathrm{mmHg}$.

Regarding the hematoma sites, 21/72 (29.2\%) were lobar, $41 / 72$ (56.9\%) were deep, and 10/72 (13.9\%) were posterior fossa ( 5 cerebellar and 5 brainstem) hematomas, and 15/72 (10.8\%) cases had intraventricular extension (IVE). Concerning the baseline HVs were $30.4 \pm 6.7,25.6 \pm 5.4,19.8$ \pm 3.6 , and $7.8 \pm 0.5 \mathrm{ml}$ for lobar, deep, cerebellar, and brainstem hematomas, respectively. Classifying $\mathrm{ICH}$ regarding the most possible etiologies showed that, 40/72 (55.6\%) cases were HTN-related S-xICH, 14/72 (19.4\%) had systemic diseases (6 hepatic decompensation, 4 had bleeding disorders, 2 hemodialysis and 2 systemic lupus erythematosus), 14/72 (19.4\%) had history of chronic use of antithrombotic drugs (8 antiplatelets and 6 oral anticoagulants), and 4/72 (5.6\%) had structural vascular lesions ( 3 arteriovenous malformation (AVM) and 1 cavernous hemangioma) (Table 1). 
The study showed that, 28/72 (38.9\%) cases developed HE (HE-group). The hematoma sites of this group were as follows: $13 / 28$ (46.4\%) deep, 12/28 (42.6\%) lobar, and 3/28 (10.7\%) infratentorial hematomas (2 cerebellar and 1 brainstem). Regarding the possible hematoma etiology, 16/28 (57.1\%) were HTN-related, 7/28 (25\%) were systemic disease-related, 4/28 (14.3\%) were medication-induced, and 1/ $28(3.6 \%)$ were structural vascular lesion-related ICH.

The HE-group showed statistically significant increase in each of patients' age, existence of smoking, and baseline mean arterial blood pressure as well as m-NIHSS compared to non-HE-group ( $p$ value $<0.05$ ). The two studied groups showed statistically non-significant differences regarding the patients' sex, existence of diabetes, and possible hematoma etiologies with a $p$ value $>0.05$ (Table 1). Regarding the NCCT findings, the HE-group displayed statistically significant increase in the initial

Table 1 Comparison between patients developed hematoma expansion (group I) and those did not (group II) regarding clinical and radiological data

\begin{tabular}{|c|c|c|c|c|}
\hline & & $\begin{array}{l}\text { Group I } \\
(n=28)\end{array}$ & $\begin{array}{l}\text { Group II } \\
(n=44)\end{array}$ & $p$ value \\
\hline \multicolumn{2}{|l|}{ Age } & $59.35 \pm 10.51$ & $54.58 \pm 8.19$ & $0.044^{*}$ \\
\hline \multirow[t]{2}{*}{ Sex } & Male & $13 / 28(46.4 \%)$ & $20 / 44(45.5 \%)$ & 0.953 \\
\hline & Female & $15 / 28(53.6 \%)$ & $24 / 44(54.5 \%)$ & \\
\hline \multicolumn{2}{|l|}{ Diabetes } & $8 / 28(28.6 \%)$ & $14 / 44(31.8 \%)$ & 0.770 \\
\hline \multicolumn{2}{|l|}{ Smoking } & $13 / 28(46.4 \%)$ & $6 / 44(13.6 \%)$ & $0.0021^{*}$ \\
\hline \multicolumn{2}{|l|}{ Smoking index } & $20.71 \pm 23.36$ & $2.5 \pm 6.77$ & $<0.0001^{*}$ \\
\hline \multicolumn{2}{|l|}{ Initial mean $A B P$} & $140.7 \pm 22.45$ & $104.3 \pm 12.97$ & $<0.0001^{*}$ \\
\hline \multicolumn{2}{|l|}{ Initial m-NIHSS } & $17.29 \pm 1.97$ & $17.2 \pm 2.74$ & $<0.0001^{*}$ \\
\hline \multicolumn{2}{|c|}{ Follow-up m-NIHSS difference } & $9.32 \pm 3.86$ & $3 \pm 1.88$ & $<0.0001^{*}$ \\
\hline \multirow[t]{4}{*}{ SMASH-U } & HTN & $16 / 28(57.1 \%)$ & $24 / 44(54.4 \%)$ & 0.385 \\
\hline & $\mathrm{Ml}$ & $4 / 28(14.3 \%)$ & $10 / 44(22.7 \%)$ & \\
\hline & SD & $7 / 28(25 \%)$ & $7 / 44(15.9 \%)$ & \\
\hline & SVL & $1 / 28(3.6 \%)$ & $3 / 44(6.8 \%)$ & \\
\hline \multirow[t]{3}{*}{ Hematoma Sites } & Lobar & $12 / 28(42.9 \%)$ & 9/44 (20.5\%) & 0.077 \\
\hline & Deep & $13 / 28(46.4 \%)$ & $28 / 44(63.6 \%)$ & \\
\hline & Infratentorial & $3 / 28(10.7 \%)$ & $7 / 44(15.9 \%)$ & \\
\hline \multicolumn{2}{|c|}{ Intraventricular extension } & 9/28 (32.1\%) & $6 / 44(13.6 \%)$ & 0.059 \\
\hline \multicolumn{2}{|c|}{ Initial hematoma volume } & $31.19 \pm 7.28$ & $21.52 \pm 5.28$ & $<0.0001^{*}$ \\
\hline \multicolumn{2}{|c|}{ Hematoma expansion volume } & $12.47 \pm 5.36$ & $1.78 \pm 0.66$ & $<0.0001^{*}$ \\
\hline \multicolumn{2}{|c|}{ Hematoma irregular border } & $17 / 28(60.7 \%)$ & $11 / 44(25 \%)$ & $0.0024^{*}$ \\
\hline \multicolumn{2}{|l|}{ Blend sign } & 9/28 (32.1\%) & $4 / 44(9.1 \%)$ & $0.013^{*}$ \\
\hline \multicolumn{2}{|l|}{ Spot sign score } & $0.84 \pm 0.76$ & $0.11 \pm 0.32$ & $<0.0001^{*}$ \\
\hline \multicolumn{2}{|l|}{ Mortality } & $15 / 28(53.6 \%)$ & $6 / 44(13.6 \%)$ & $0.0003^{*}$ \\
\hline \multicolumn{2}{|c|}{ Modified Rankin Scale } & $4.72 \pm 1.24$ & $3.1 \pm 1.008$ & $<0.0001^{*}$ \\
\hline
\end{tabular}

$A B P$ arterial blood pressure, HTN hypertension, $M I$ medication induced, $m$ NIHSS modified National Institute of Health stroke scale, SD systemic disease, SVL structural vascular lesion

*Significant hematoma volume and the existence of irregular border as well as blend sign compared to the non-HE-group with $p$ value $<0.05$ (Table 1, Fig. 1). Regarding the blend sign's sensitivity, specificity, positive predictive value, and negative predictive value for $\mathrm{HE}$ expectations were $32 \%, 90 \%, 69 \%$, and $68 \%$, respectively. The two studied groups displayed statistically non-significant difference regarding the hematoma sites and existence of IVE with a $p$ value $>0.05$ (Table 1 ).

The results of the CTA revealed that the HE-group exhibited statistically significant increase in the SSS compared to the non-HE-group with a $p$ value $<0.05$ (Table 1, Figs. 2 and 3). The sensitivity, specificity, positive predictive value, and negative predictive value of the SSS for expectation of impending HE were 54\%, 91\%, $79 \%$, and $75 \%$, respectively. The SSS was positively correlated with the initial $\mathrm{HV}$, the degree of increase in each of HV and m-NIHSS, patients' mortality, and the MRS. The score was not correlated with the patients' age and the initial mean ABP (Fig. 4).

During the 3-month follow-up period, 21 patients died and 8 cases were dropped out. The HE-group showed higher mortality, increased disability, and poorer functional outcome (as measured by MRS) than non-HEgroup with a $p$ value $<0.05$ (Table 1 ).

\section{Discussion}

Spontaneous ICH is not a monophasic event, but the size of the hematoma grows in the next hours after the onset which results in worse functional outcome and higher mortalities. Prediction of the approaching HE is a crucial inlet to improve ICH management and prognosis as it allows early intervention before irreversible brain damage and herniation take place [14].

The results of the present study revealed that $\mathrm{HE}$ occurred in approximately $40 \%$ of S-ICH patients who were subjected to higher mortality, increased degree of disabilities, and lower functional independence than those who did not develop HE. These results are in harmony with the work of Morotti and colleagues [15] as well as $\mathrm{Yu}$ and colleagues [16] who stated that a high proportion of SICH patients are subjected to re-bleeding within few hours from stroke onset, and they recommended routine NCCT repetition for all S-ICH patients in purpose of early HE detection. The researches also showed that hematoma growth is one of the leading causes of early clinical deterioration and increased mortality in S-ICH patients undergoing conservative and/or surgical management.

The present study revealed that, risk of HE was higher among patients with high admission mean ABP which is in harmony with the works of Takeda and colleagues [17] as well as Lattanzi and colleagues [18] who identified increased risks of HE among those with high admission $\mathrm{ABP}$, and they recommended early intensive blood 


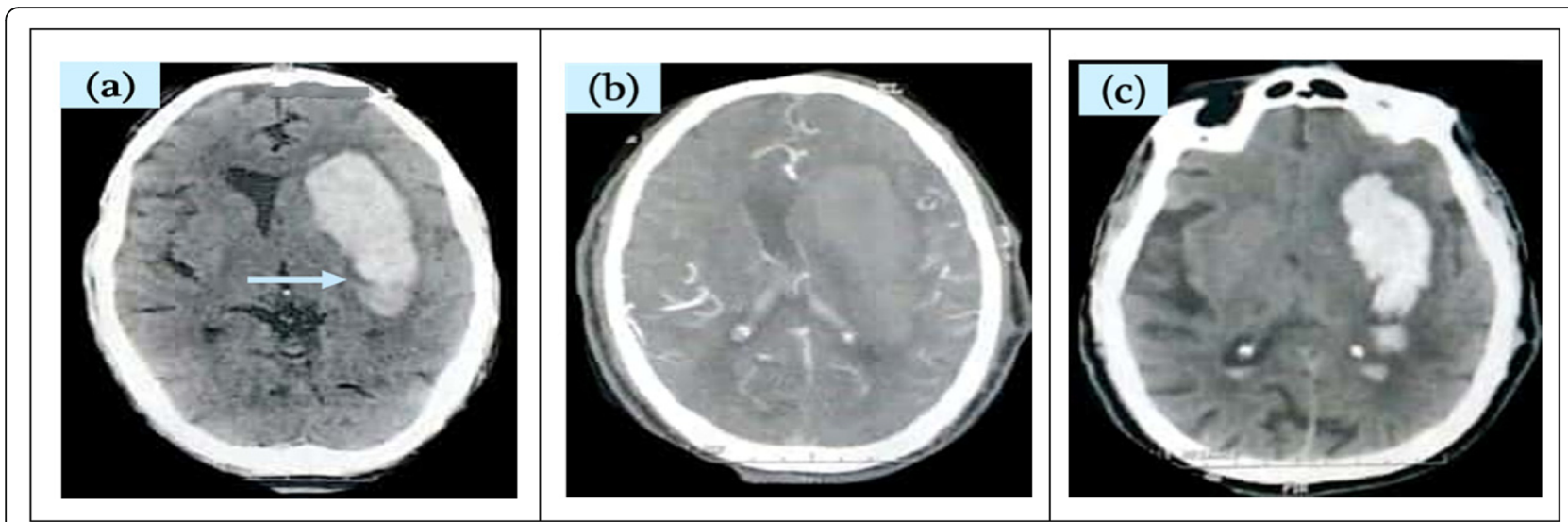

Fig. 1 a Baseline CT shows a hematoma with two components (blend sign). b CTA with absent spot sign. $\mathbf{c}$ 48-h follow-up without hematoma expansion

pressure-lowering in $\mathrm{S}-\mathrm{ICH}$ patients to reduce the risk of $\mathrm{HE}$ and subsequent early clinical deterioration. On the other hand, Morotti and colleagues [15] are skeptical about this result as they found no evidences of getting benefits from intensive blood pressure reduction in S-ICH patients and they assert that elevated blood pressure is the consequence of rapid elevation in the intracranial pressure and damage of the central autonomic centers by the growing hematoma.

This work declared that the risk of HE is higher among elderly, smokers, and those with high admission m-NIHSS while patients' gender and existence of diabetes had no relation with the risk of hematoma re-bleeding. These remarks are in accordance with the results of An and colleagues [19] as well as Engel-Haber and colleagues [20] who stated that old age and smoking are associated with poor functional outcome and higher mortality in S-ICH patients due to their induced angiopathic changes which results in high incidence of re-hemorrhage and HE. The work of Sakuta and colleagues [21] agrees with that high initial m-NIHSS carries a very high risk following HE but they also excluded high admission $\mathrm{ABP}$ as a risk of $\mathrm{HE}$ and instead of high admission random blood sugar with cutoff value of $\geq 133 \mathrm{mg} / \mathrm{dl}$ as a risk of HE. These discrepancies in the latter results between their study and the present one may be related to different selection criteria with older age and lower initial HV of their studied patients.

The NCCT represents the gold standard in ICH diagnosis and is widely available in all stroke centers. The study showed that, risk of HE was possible in both supratentorial and infratentorial hematomas. At the

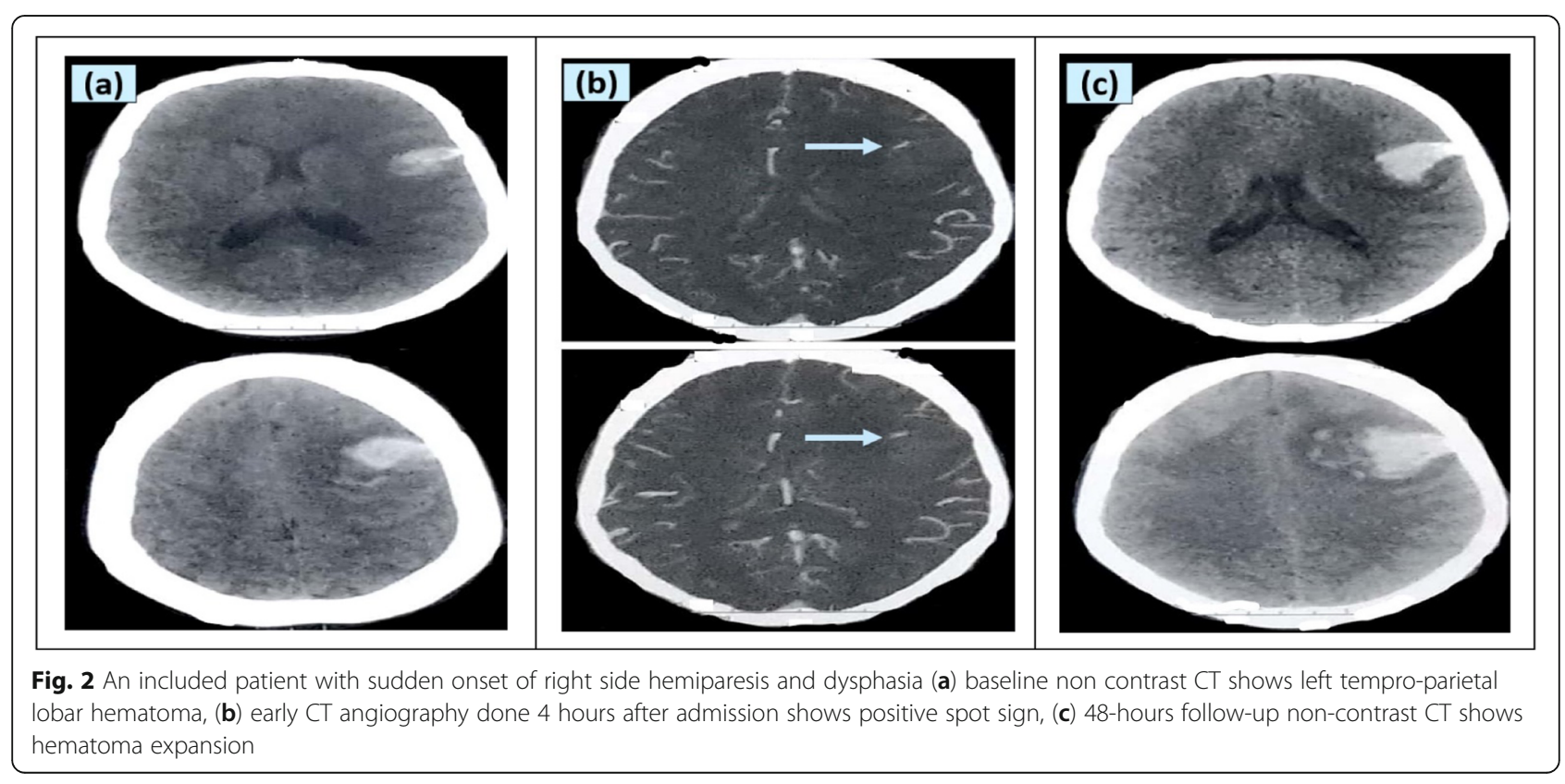




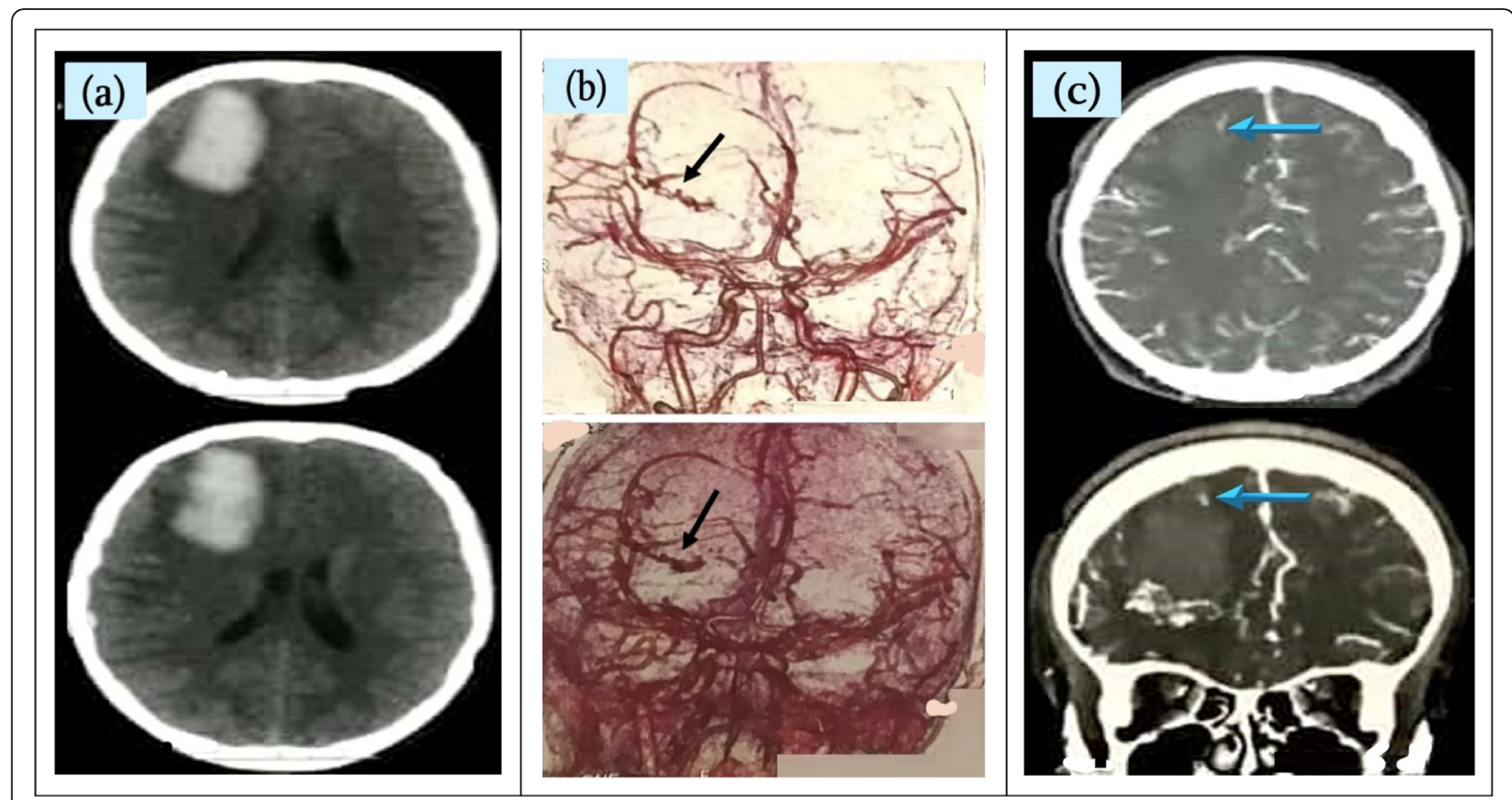

Fig. 3 An included patient presented by sudden onset of severe frontal headache, repeated vomiting and focal fits; a Initial non-contrast CT shows right frontal hematoma, b CT angiography shows AVM nidus (arrow), c The CT angiography shows spot sign detected in both axial and coronal sections (arrow)

same time, HTN, systemic diseases, and medication-induced ICH carried the same risk of HE. These results are in accordance with the work of Cappellari and colleagues [22] who declared that certain etiologic S-ICH subtypes are more prone to risk of HE including HTN, systemic diseases related, and medication induced. They also stated that large volume lobar supratentorial hematomas are more liable for re-bleeding than infratentorial ones. All at once, Morotti and colleagues [23] determined many hematoma sizes increase and consequent poorer prognosis among their included brainstem hematomas patients.
The results also declared that, NCCT predictors of HE included large volume, irregular border, and the presence of blend sign. These results are in accordance with the works of Zheng and colleagues [24] as well as Lei and colleagues [25] who stated that large $\mathrm{HV}$ and irregular border are independent NCCT predictors of impending hematoma growth. At the same time, the study of Morotti and colleagues [26] stated that identification of the blend sign is not only an imaging biomarker of impending HE but also a good prognostic indicator of poor functional outcome and higher mortality.

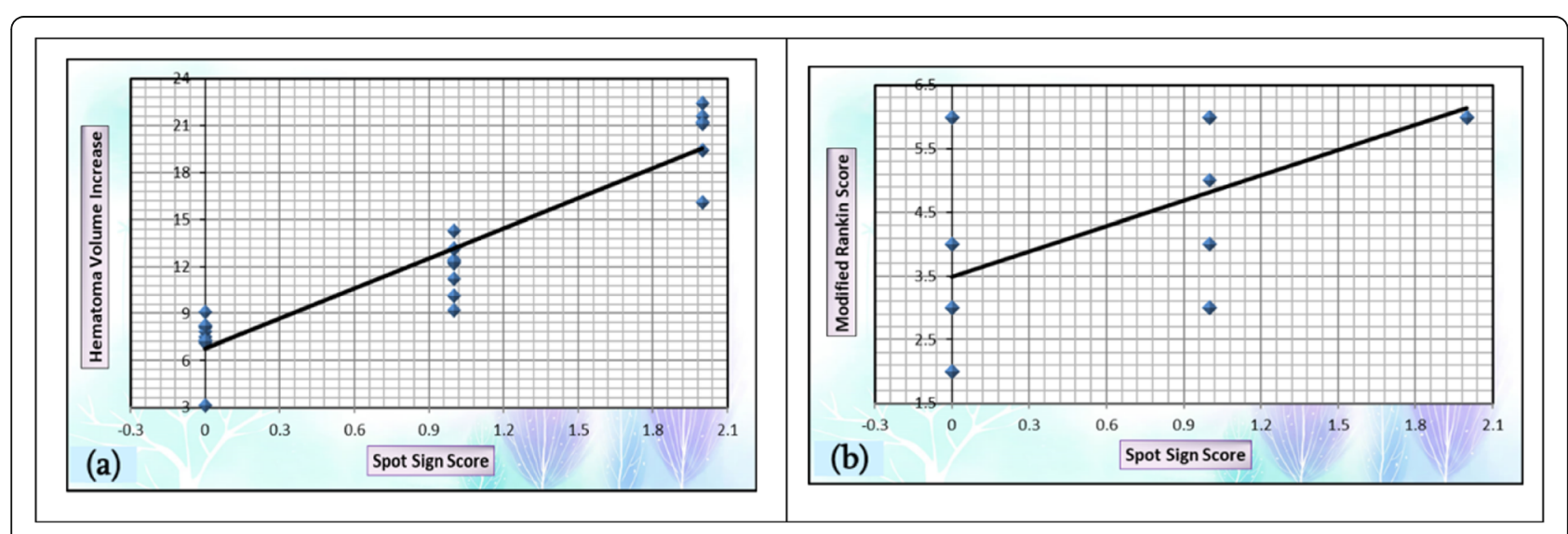

Fig. 4 a, b Positive correlations between spot sign score and each of increased hematoma volume and modified Rankin scale 
Contrast extravasation to the hematoma cavity is an indicator of ongoing active bleeding process and a predictor of subsequent HE [27]. The study revealed that, CTA spot sign had carried high sensitivity and specificity for the prediction of impending HE exceeded that of NCCT findings which included the blend sign. At the same time, higher SSS was associated with increased early mortality and degree of subsequent physical disability. These results are in accordance with the study of $\mathrm{Yu}$ and colleagues [28] as well as Ovesen and colleagues [29] who stated that CTA spot sign is associated with increased risk of re-bleeding and hematoma growth, poorer functional outcome, and higher mortality especially in supratentorial hematomas.

\section{Conclusion}

Early post-admission HE is a major determinant of clinical deterioration, worsened functional outcome, and increased mortality following S-ICH. Risks of HE included old age, smoking, and high initial mean ABP as well as $\mathrm{m}$-NIHSS. Spot sign in CTA is a reliable predictor of impending $\mathrm{HE}$, but in the presence of contrast contraindications or absence of facilities to do CTA, the NCCT findings as large $\mathrm{HV}$, irregular border, and/or blend sign can be relied on re-bleeding expectation.

\section{Limitations}

The controversy about the value of neurosurgical intervention and the high rate of reported post-surgical mortalities enforced many patients' relatives to refuse surgical hematoma evacuation which limited precise assessment of the value of such management plan. At the same time, the short interval needed to stabilize patients' medical state before their transfer to do CTA besides the additional risks of their exposure to iodinated contrast material and high dose of radiation had put a big proportion of patients in the exclusion criteria.

\section{Additional file}

Additional file 1: CTA spot sign. (DOCX $38 \mathrm{~kb})$

\section{Abbreviations}

ABP: Arterial blood pressure; AVM: Arteriovenous malformation; CTA: CT angiography; HE: Hematoma expansion; HTN: Hypertension; HV: Hematoma volume; ICH: Intracerebral hemorrhage; IVE: Intraventricular extension; MRS: Modified Rankin scale; NCCT: Non-contrast CT; m-NIHSS: Modified National Institute of Health stroke scale; S-ICH: Spontaneous intracerebral hemorrhage; SSS: Spot sign score

\section{Acknowledgements}

We would like to thank the ICU and neuro-intervention teams of Neuropsychiatry Department, Tanta University Hospitals for their great help in patients' selection, evaluation, management, and follow-up.

Consent of publication

Not applicable.

\section{Authors' contributions}

$\mathrm{HHAH}$ participated in the patient assessment and inclusion, imaging interpretation, statistical analysis, references collection, and manuscript writing. WSB participated in the study's idea, design, patient selection, examination, follow-up, statistical analysis, data analysis, references collection, and manuscript writing, revision, and final approval. AAG participated in the study's idea, design, patient selection, examination, follow-up, statistical analysis, data analysis, and manuscript revision and final approval. MOR participated in the study's idea and design, patient selection, imaging interpretation, data analysis, and manuscript revision and final approval. All authors read and approved the final manuscript.

\section{Funding}

No funding had been received.

Availability of data and materials

The datasets used and/or analyzed during the current study are available from the corresponding author on reasonable request.

\section{Ethics approval and consent to participate}

The manuscript was approved by The Research Ethics Committee and Quality Assurance Unit, Faculty of Medicine, Tanta University (the URL: http:// tqac.tanta.edu.eg/new-tqac/; QualityAssuranceUnit@hotmail.com; Approval Code: 31300/01/17; name of the PI: Hany Hamed Abd Elhady Helal; name of the department: Neuropsychiatry Department; type of the research: MSc thesis; date of approval: January 2017).

The study's protocol was approved by The Research Ethics Committee and Quality Assurance Unit, Faculty of Medicine, Tanta University. Participations were voluntary, any possible risks were clarified, and informed written consents were approved by all participants' or their guardians.

\section{Competing interests}

All authors declare that they have no competing interests.

\section{Author details}

${ }^{1}$ Tanta University Hospitals, Tanta, Egypt. ${ }^{2}$ Faculty of Medicine, Tanta University, Tanta, Egypt. ${ }^{3}$ Department of Neurology, Faculty of Medicine, Tanta University, Tanta 31527, Egypt.

Received: 11 October 2018 Accepted: 21 August 2019

Published online: 05 September 2019

\section{References}

1. Kim JY, Bae HJ. Spontaneous intracerebral hemorrhage: management. J Stroke. 2017:19(1):28-39. https://doi.org/10.5853/jos.2016.01935.

2. Krishnamurthi RV, Moran AE, Forouzanfar MH, Bennett DA, Mensah GA, Lawes CM, et al. The global burden of hemorrhagic stroke: a summary of findings from the GBD 2010 study. Glob Heart. 2014;9(1):101-6. https://doi. org/10.1016/j.gheart.2014.01.003.

3. Veltkamp R, Purrucker J. Management of spontaneous intracerebral hemorrhage. Curr Neurol Neurosci Rep. 2017;17(10):80. https://doi.org/10.1 007/s11910-017-0783-5

4. Delcourt C, Huang Y, Arima H, Chalmers J, Davis SM, Heeley EL, et al. Hematoma growth and outcomes in intracerebral hemorrhage: the INTERACT1 study. Neurology. 2012;79(4):314-9. https://doi.org/10.1212/WNL. Ob013e318260cbba.

5. Wang X, Arima H, Salman RA, Woodward M, Heeley E, Stapf C, et al. Clinical prediction algorithm (BRAIN) to determine risk of hematoma growth in acute intracerebral hemorrhage. Stroke. 2015;46(2):376-81. https://doi.org/1 0.1371/journal.pone.0115777.

6. Du FZ, Jiang R, Gu M, He C, Guan J. The accuracy of spot sign in predicting hematoma expansion after intracerebral hemorrhage: a systematic review and meta-analysis. PLoS One. 2014;9(12):e115777. https://doi.org/10.1371/ journal.pone.0115777.

7. Meyer BC, Lyden PD. The Modified National Institutes of Health Stroke Scale (mNIHSS): Its Time Has Come. Int J Stroke. 2009;4(4):267-73. https://doi. org/10.1111/j.1747-4949.2009.00294.x.

8. Hemphill JC, Greenberg SM, Anderson CS, Becker K, Bendok BR, Cushman $M$, et al. Guidelines for the management of spontaneous intracerebral hemorrhage: a guideline for healthcare professionals from the American 
Heart Association/American Stroke Association. Stroke. 2015;46(7):2032-60. https://doi.org/10.1161/STR.0000000000000069.

9. Banks JL, Marotta CA. Outcomes Validity and reliability of the modified Rankin scale: implications for stroke clinical trials. Stroke. 2007;38:1091-6. https://doi.org/10.1161/01.STR.0000258355.23810.c6.

10. Sporns PB, Schwake M, Kemmling A, Minnerup J, Schwindt W, Niederstadt T, et al. Comparison of spot sign, blend sign and black hole sign for outcome prediction in patients with ICH. J Stroke. 2017;19(3):333-9. https:// doi.org/10.5853/jos.2016.02061

11. Almandoz JED, Yoo AJ, Stone MJ, Schaefer PW, Oleinik A, Brouwers HB, et al. The spot sign score in primary intracerebral hemorrhage identifies patients at highest risk of in-hospital mortality and poor outcome among survivors. Stroke. 2010;41:54-60. https://doi.org/10.1161/STROKEAHA.109.565382.

12. Salman RAS, Frantzias J, Lee RJ, Lyden PD, Battey TWK, Ayres AM, et al. Absolute risk and predictors of the growth of acute spontaneous ICH: a systematic review and meta-analysis of individual patient data. Lancet. 2018; 17(10):885-94. https://doi.org/10.1016/S1474-4422(18)30253-9.

13. Meretoja A, Strbian D, Putaala J, Curtze S, Haapaniemi E, Mustanoja S, et al. SMASH-U A proposal for etiologic classification of ICH. Stroke. 2012;43:25927. https://doi.org/10.1161/STROKEAHA.112.661603.

14. Elsaeed Egila AA, Khodair RM, Faheem MK, Kasem SM. Hematoma expansion in spontaneous intracerebral hemorrhage. Benha Med J. 2017; 34(1):37-42. https://doi.org/10.4103/1110-208X.206904.

15. Morotti A, Boulouis G, Romero JM, Brouwers HB, Jessel MJ, Vashkevich A, Schwab K, et al. Blood pressure reduction and non-contrast $C T$ markers of intracerebral hemorrhage expansion. Neurology. 2017;89:1-7. https://doi. org/10.1212/WNL.0000000000004210.

16. Yu Z, Zheng J, Guo R, Ma L, Li M, Wang X, Lin S, et al. Prognostic significance of ultra-early hematoma growth in spontaneous $\mathrm{ICH}$ patients receiving hematoma evacuation. World Neurosurgery. 2018;109:651-4. https://doi.org/10.1016/j.wneu.2017.10.049

17. Takeda R, Ogura T, Ooigawa H, Fushihara G, Yoshikawa S, Okada D, et al. A practical prediction model for early hematoma expansion in spontaneous deep ganglionic ICH. Clin Neurol Neurosurg. 2013;115(7):1028-31. https:// doi.org/10.1016/j.clineuro.2012.10.016.

18. Lattanzi S, Cagnetti C, Provinciali L, Silvestrini M. How should we lower blood pressure after cerebral hemorrhage? A systematic review and meta-analysis. Cerebrovasc Dis. 2017:43:207-13. https://doi.org/10.1159/000462986.

19. An SJ, Kim TJ, Yoon BW. Epidemiology, risk factors, and clinical features of intracerebral hemorrhage: an update. J Stroke. 2017:19(1):3-10. https://doi. org/10.5853/jos.2016.00864

20. Engel-Haber E, Horev A, Chablani P, Bornstein NM, Jadhav A, Jovin TG, et al. Aspirin response test role in platelet transfusion following $\mathrm{ICH}$. Clinical Neurology and Neurosurgery. 2015;137:12-4. https://doi.org/10.1016/j. clineuro.2015.06.007.

21. Sakuta K, Sato T, Komatsu T, Sakai K, Terasawa Y, Mitsumura H, Iguchi Y. The NAG scale: noble predictive scale for hematoma expansion in intracerebral hemorrhage. J Stroke Cerebrovasc Dis. 2018;27(10):2606-12. https://doi. org/10.1016/j.jstrokecerebrovasdis.2018.05.020.

22. Cappellari M, Zivelonghi C, Moretto G, Micheletti N, Carletti M, Tomelleri G, et al. The etiologic subtype of intracerebral hemorrhage may influence the risk of significant hematoma expansion. J Neurol Sci. 2015;359:293-7. https://doi.org/10.1016/j.jns.2015.11.024.

23. Morotti A, Jessel MJ, Brouwers HB, Falcone GJ, Schwab K, Ayres AM, et al. CT angiography spot sign, hematoma expansion, and outcome in primary pontine ICH. Neurocrit Care. 2016;25(1):79-85. https://doi.org/10.1007/s1202 8-016-0241-2.

24. Zheng J, Yu Z, Guo R, Li H, You C, Ma L. Meta-analysis of predictive significance of the black hole sign for hematoma expansion in $\mathrm{ICH}$. World Neurosurgery. 2018;115:711-6. https://doi.org/10.1016/j.wneu.2018.04.140.

25. Lei C, Geng J, Chen C, Chang X. Accuracy of the blend sign on CT as a predictor of hematoma growth after spontaneous ICH: a systematic review. J Stroke Cerebrovasc Dis. 2018;27(6):1705-10. https://doi.org/10.1016/j. jstrokecerebrovasdis.2018.01.032.

26. Morotti A, Dowlatshahi D, Boulouis G, Al-Ajlan F, Demchuk AM, Aviv Rl, et al. Predicting intracerebral hemorrhage expansion with non-contrast computed tomography: the BAT Score. Stroke. 2018;49(5):1163-9. https:// doi.org/10.1161/STROKEAHA.117.020138.

27. Du FZ, Jiang R, Gu M, He C, Guan J. The accuracy of spot sign in predicting hematoma expansion after ICH: a systematic review and meta-analysis. PLoS ONE. 2014;9(12):e115777. https://doi.org/10.1371/journal.pone.0115777.
28. Yu Z, Ma L, Zheng J, Guo R, Li M, Wang X, et al. Comparison of hematoma density heterogeneity and ultra-early hematoma growth in predicting hematoma expansion in patients with spontaneous intracerebral hemorrhage. J Neurol Sci. 2017;379:44-8. https://doi.org/10.1016/j.jns.2017. 05.049.

29. Ovesen C, Havsteen I, Rosenbaum S, Christensen H. Prediction and observation of post-admission hematoma expansion in patients with intracerebral hemorrhage. Front Neurol. 2014;5:186):1-12. https://doi.org/1 0.3389/fneur.2014.00186.

\section{Publisher's Note}

Springer Nature remains neutral with regard to jurisdictional claims in published maps and institutional affiliations.

\section{Submit your manuscript to a SpringerOpen ${ }^{\circ}$ journal and benefit from:}

- Convenient online submission

- Rigorous peer review

- Open access: articles freely available online

High visibility within the field

- Retaining the copyright to your article

Submit your next manuscript at $\boldsymbol{\nabla}$ springeropen.com 